\title{
Effects of inspired oxygen fraction in discriminating venous from arterial blood in percutaneous central venous catheterization under general anesthesia
}

\author{
Dong Yun Lim, Dae Wook Lee, Eun Ah Jang, Seong Heon Lee, Hye Jin Jeong, Cheol Won Jeong, \\ Seong Wook Jeong, and Kyung Yeon Yoo \\ Department of Anesthesiology and Pain Medicine, Chonnam National University Medical School, Gwangju, Korea
}

Background: A low fraction of inspired oxygen $\left(\mathrm{FiO}_{2}\right)$ increases venous deoxygenated hemoglobin concentrations, making the color of the blood darker. The present study was aimed to determine the effects of $\mathrm{FiO}_{2}$ on the ability to discriminate venous from arterial blood.

Methods: One-hundred and sixty surgical patients undergoing percutaneous central venous access of the internal jugular vein were randomly assigned to receive $a n \mathrm{FiO}_{2}$ of $0.2,0.4,0.6$, or $1.0(\mathrm{n}=40$ each) for at least 20 min prior to central line placement under general anesthesia. Vascular access was achieved with a 22-gauge needle; $2 \mathrm{ml}$ of blood was withdrawn and shown to three physicians including the operator. Each of them was asked to identify the blood as 'arterial,' 'venous' or 'not sure'. Simultaneous blood gas analysis of the samples was performed on blood taken from the puncture site and the artery after visual comparison to confirm blood's origin and hemodynamic measurements. Results: Lowering $\mathrm{FiO}_{2}$ progressively increased venous deoxygenated hemoglobin concentrations $(2.24 \pm 1.12,3.30 \pm$ $1.08,3.66 \pm 1.15$, and $3.71 \pm 1.33 \mathrm{~g} / \mathrm{dl})$ in groups having an $\mathrm{FiO}_{2}$ of 1.0, 0.6, 0.4 and 0.2 , respectively $(\mathrm{P}<0.001)$, thereby facilitating the 'venous' blood identification $(\mathrm{P}<0.001)$. Neither heart rate nor mean arterial pressure differed among the groups. None developed hypoxemia (percutaneous hemoglobin oxygen saturation $<90 \%$ ) in any group during the study period.

Conclusions: A low $\mathrm{FiO}_{2}$ increases venous deoxygenated hemoglobin levels, thereby facilitating the recognition by clinicians of its venous origin in percutaneous central venous catheterization under general anesthesia. (Korean J Anesthesiol 2012; 62: 225-229)

Key Words: Central venous catheter techniques, Complication, Inspired oxygen fraction.

\footnotetext{
Received: May 2, 2011. Revised: May 27, 2011. Accepted: June 9, 2011.

Corresponding author: Kyung Yeon Yoo, M.D., Ph.D., Department of Anesthesiology and Pain Medicine, Chonnam National University Medical School, 671, Jebongno, Dong-gu, Gwangju 501-757, Korea. Tel: 82-62-220-6893, Fax: 82-62-232-6294, E-mail: kyyoo@jnu.ac.kr (c) This is an open-access article distributed under the terms of the Creative Commons Attribution Non-Commercial License (http:// creativecommons.org/licenses/by-nc/3.0/), which permits unrestricted non-commercial use, distribution, and reproduction in any medium, provided the original work is properly cited.
} 


\section{Introduction}

Central venous catheterization is widely used for extended intravenous (i.v.) drug administration, fluid resuscitation, parenteral nutrition, emergent cardiac pacing, dialysis and central cardiovascular monitoring. Unfortunately, it has been associated with many acute and long-term complications [1,2]. Among them are inadvertent arterial puncture with unplanned arterial dilations or cannulations [3], severe morbidity and mortality rates of which have been reported [4]. One may verify an arterial puncture during needle localization of the internal jugular vein (IJV) by blood color [5]. Blood assumes a darker color as the amount of deoxygenated hemoglobin increases: at $5 \mathrm{~g} / \mathrm{dl}$ in the capillaries, cyanosis is apparent in a fair-skinned person [6].

Oxygen consumption, especially in brain, is decreased in the presence of anesthesia $[7,8]$. In addition, changes in respiratory function may require oxygen supplementation [fraction of inspired oxygen $\left(\mathrm{FiO}_{2}\right)>60 \%$ ] in patients under general anesthesia [9]. Both of these factors in anesthetized patients may increase oxygen tension of central venous blood with less deoxygenated hemoglobins, and hence the blood would be less dark and less discriminating. Thus, the reduction of $\mathrm{FiO}_{2}$ under general anesthesia while placing central venous catheters would be helpful in discriminating venous from arterial blood. Although the examination of blood color is something all clinicians do as part of their routine, it has never been tested in relation to use of a lower $\mathrm{FiO}_{2}$ during needle localization of the IJV in a prospective fashion. The present study was aimed to evaluate the effects of different $\mathrm{FiO}_{2} \mathrm{~s}$ on the ability to discriminate venous from arterial blood in patients undergoing central venous catheterization under general anesthesia.

\section{Materials and Methods}

The protocol was approved by the institutional review board and informed consent was obtained from each patient. One hundred and sixty American Society of Anesthesiologists physical status I-III adult surgical patients, undergoing percutaneous central venous access of the IJV, were studied. Exclusion criteria were all other central venous access techniques and all other vessels, atrial septal defects, emergency surgery, current treatment with cardio-active drugs and age < 18 or $>70$ years. Percutaneous hemoglobin oxygen saturation $\left(\mathrm{SpO}_{2}\right)$ was measured continuously using pulse oximetry. Patients who developed a pulse oximetry reading of $\mathrm{SpO}_{2}<90 \%$ during the period of study were also excluded.

All patients were premedicated with midazolam $(0.1 \mathrm{mg} / \mathrm{kg})$ orally $60 \mathrm{~min}$ before the induction of anesthesia. Upon arrival in the operating room, Ringer's lactate solution was initiated at a rate of $10 \mathrm{ml} / \mathrm{kg} / \mathrm{h}$. A 20-gauge catheter was placed into a radial artery to continuously monitor blood pressure and to take blood samples for arterial blood gas analysis.

After preoxygenation, anesthesia was induced with i.v. administration of $5-7 \mathrm{mg} / \mathrm{kg}$ thiopental sodium, $2-3 \mu \mathrm{g} /$ $\mathrm{kg}$ of fentanyl and $0.8 \mathrm{mg} / \mathrm{kg}$ of rocuronium, and maintained with $1.2 \%$ to $2.0 \%$ sevoflurane (inspired) following tracheal intubation. Patients were randomly assigned to receive an $\mathrm{FiO}_{2}$ of either 1.0, 0.6, 0.4 or 0.2 ( $\mathrm{n}=40$ each) initiating immediately after intubation. Patients' lungs were mechanically ventilated to maintain an end-tidal carbon dioxide $\left(\mathrm{CO}_{2}\right)$ tension between 35 and $40 \mathrm{mmHg}$ with a fresh gas flow of $4 \mathrm{~L} / \mathrm{min}$. After induction of anesthesia, all patients were placed into the 15 to $30^{\circ}$ Trendelenburg position and then we attempted to locate the vein with a searching needle after sterile skin preparation. We maintained the designated $\mathrm{FiO}_{2}$ at least $20 \mathrm{~min}$ prior to and throughout the procedure. The right IJV was typically selected for access; when attempts failed, the left IJV was selected.

All physicians followed the same basic procedure of using a 22-gauge searching needle to locate the IJV and $2 \mathrm{ml}$ of blood was withdrawn. The blood samples within the syringe were displayed to three inspectors including the operator in random order under operating room light conditions immediately after collection. Each of them was asked to identify whether the blood was 'arterial, 'venous' or 'not sure' and their responses were recorded. Immediately thereafter, the color of blood sampled from the searching needle was directly compared with that taken from a previously inserted arterial catheter and then blood gas analysis of both samples were done using a blood gas/electrolyte analyzer $\left(\mathrm{GEM}^{\circledR}\right.$ Premier 3000, Instrumentation Laboratory, Lexington, USA) to confirm the location of the searching needle, and to measure oxygen and carbon dioxide tensions, oxygen saturation and pH. Hemoglobin concentrations using the Hematology System (ADVIA 120, Bayer Healthcare LLC, NY, USA) to calculate reduced hemoglobin concentration by subtracting oxygenated from total hemoglobin concentrations, and arterial blood pressure and heart rate (HR) were also measured. In patients whose blood from the searching needle turned out to be arterial by comparing with in situ arterial blood and blood gas analyses, the procedure was continued until venous blood was obtained.

A central venous catheter was then inserted using the Seldinger technique by physicians who ranged in experience from resident physicians in their second year of anesthesia training to consultants with 30 year of anesthesia experience. Catheter-tip location was checked by X-ray with a final destination in the superior vena cava, outside the pericardium, to avoid the danger of complications such as cardiac tamponade. Monitoring included electrocardiogram, pulse oximetry, invasive blood pressure, end-tidal $\mathrm{CO}_{2}$ and central venous pressure. 
Table 1. Demographic Characteristics

\begin{tabular}{lcccc}
\hline & & \multicolumn{3}{c}{$\mathrm{FiO}_{2}$} \\
\cline { 2 - 5 } & 1.0 & 0.6 & 0.4 & 0.2 \\
$(\mathrm{n}=40)$ & $(\mathrm{n}=40)$ & $24 / 16$ & $21 / 19$ \\
\hline Gender (M/F) & $25 / 15$ & $26 / 14$ & $49.8 \pm 13.9$ & $50.5 \pm 12.4$ \\
Age (yr) & $54.0 \pm 13.7$ & $52.8 \pm 13.1$ & $164.8 \pm 8.5$ & $162.5 \pm 10.3$ \\
Height (cm) & $163.3 \pm 9.6$ & $164.8 \pm 6.9$ & $63.0 \pm 10.4$ & $59.5 \pm 10.3$ \\
Weight (kg) & $60.9 \pm 11.4$ & $61.1 \pm 9.9$ & \\
\hline
\end{tabular}

Values are means \pm SD or number of patients. There were no differences among the groups. $\mathrm{FiO}_{2}$ : inspired oxygen fraction during catheterization.

Table 2. Hemodynamic Data and Arterial and Central Venous Blood Gas Values

\begin{tabular}{|c|c|c|c|c|}
\hline & \multicolumn{4}{|c|}{$\mathrm{FiO}_{2}$} \\
\hline & $\begin{array}{c}1.0 \\
(\mathrm{n}=40)\end{array}$ & $\begin{array}{c}0.6 \\
(n=40)\end{array}$ & $\begin{array}{c}0.4 \\
(\mathrm{n}=40)\end{array}$ & $\begin{array}{c}0.2 \\
(\mathrm{n}=40)\end{array}$ \\
\hline MAP (mmHg) & $94 \pm 20$ & $89 \pm 18$ & $91 \pm 25$ & $91 \pm 27$ \\
\hline HR (beats/min) & $78 \pm 12$ & $79 \pm 15$ & $77 \pm 14$ & $77 \pm 11$ \\
\hline $\mathrm{PaO}_{2}(\mathrm{mmHg})$ & $445 \pm 111$ & $257 \pm 72 *$ & $158 \pm 46^{*, \dagger}$ & $80 \pm 10 *$, † \\
\hline $\mathrm{SaO}_{2}(\%)$ & $100.0 \pm 0.2$ & $99.9 \pm 0.2$ & $99.2 \pm 1.5^{*,+}$ & $96.1 \pm 2.5^{*,+, キ}$ \\
\hline $\mathrm{PvO}_{2}(\%)$ & $50.5 \pm 10.3$ & $43.1 \pm 7.1^{*}$ & $39.4 \pm 7.0^{*, \dagger}$ & $39.3 \pm 7.1^{*, \dagger}$ \\
\hline $\mathrm{SvO}_{2}(\%)$ & $82.4 \pm 8.3$ & $75.2 \pm 7.9 *$ & $71.2 \pm 8.6^{*, \dagger}$ & 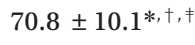 \\
\hline $\mathrm{Hb}(\mathrm{g} / \mathrm{dl})$ & $12.3 \pm 1.9$ & $13.4 \pm 1.6$ & $12.8 \pm 1.8$ & $12.8 \pm 1.6$ \\
\hline Deoxygenated $\mathrm{Hb}$ (g/dl) & $2.24 \pm 1.12$ & $3.30 \pm 1.08^{*}$ & $3.66 \pm 1.15^{*}$ & $3.71 \pm 1.33^{*, \dagger, \dagger}$ \\
\hline
\end{tabular}

Values are means $\pm \mathrm{SD}$. $\mathrm{FiO}_{2}$ : inspired oxygen fraction, MAP:mean arterial blood pressure, $\mathrm{HR}$ : heart rate, $\mathrm{PaO}_{2}$ : arterial oxygen tension, $\mathrm{SaO}$ : arterial oxygen saturation, $\mathrm{PvO}_{2}$ : central venous oxygen tension, $\mathrm{SvO}_{2}$ : central venous oxygen saturation, Hb: hemoglobin. $* \mathrm{P}<0.05$ versus 1.0 , ${ }^{\dagger} \mathrm{P}<0.05$ vs. $0.6,{ }^{\dagger} \mathrm{P}<0.05$ versus 0.4 .

The sample size was calculated based on our preliminary data of deoxygenated hemoglobin $\left(n=5\right.$ each) using $\mathrm{G}^{*}$ Power 3.1.2 [10]. The observed main effect was $F=2.66$, effect size $\mathrm{f}$ $=0.338$ and power 0.95 . Thus, a sample size of 39 patients was suggested in each group.

Data are expressed as number or means \pm SD. They were analyzed using StatView software version 4.0 (Abacus Concepts, CA, USA) on a Macintosh computer. Categorical data were analyzed using a Fisher's exact-test. Other data were compared among the groups using one-way analysis of variance followed by Scheffè's post-hoc testing as required. A P value of $<0.05$ was considered statistically significant.

\section{Results}

There were no significant differences among the groups with respect to sex ratio, age, height or weight (Table 1). Onehundred and seventy-five punctures were performed for 160 patients, in which 15 (8.6\%) were repeated because of arterial puncture.

Decreasing $\mathrm{FiO}_{2}$ from 1.0 caused a progressive decrease in central venous oxygen saturation $\left(\mathrm{SvO}_{2}\right): 82.4 \pm 8.3,75.2 \pm 7.9$, $71.2 \pm 8.6$ and $70.8 \pm 10.1 \%$ in the groups breathing $100,60,40$ and $20 \%$ oxygen, respectively $(\mathrm{P}<0.001)$. The concentrations of deoxygenated hemoglobin were $2.24 \pm 1.12,3.30 \pm 1.08$,

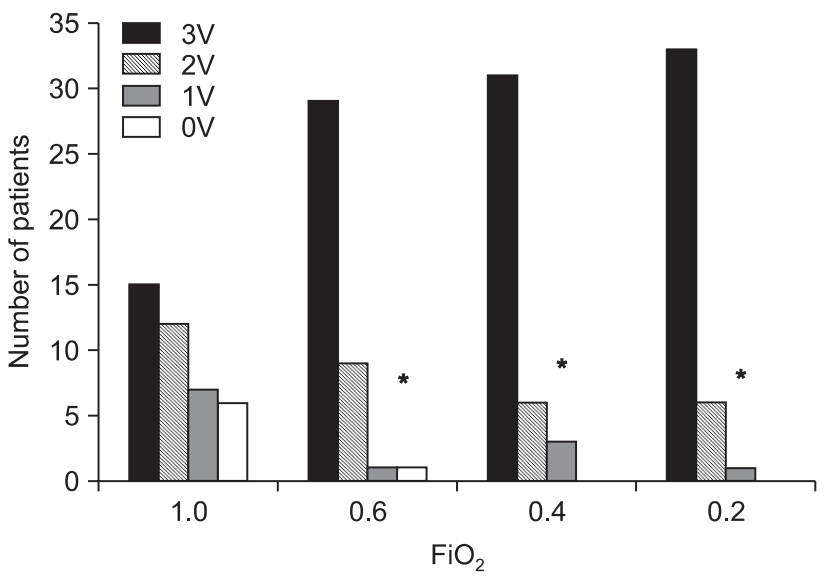

Fig. 1. Distribution of the number of patients identified by three, two or one inspectors in patients receiving different inspired oxygen fractions $\left(\mathrm{FiO}_{2}\right)$ during central line placement. $3 \mathrm{~V}, 2 \mathrm{~V}, 1 \mathrm{~V}$ and $0 \mathrm{~V}$ represent $3,2,1$, and 0 physicians discriminated venous as venous blood, respectively. ${ }^{*} \mathrm{P}<0.001$ compared with 1.0 .

$3.66 \pm 1.15$ and $3.71 \pm 1.33 \mathrm{~g} / \mathrm{dl}$, respectively. Eleven patients $(27.5 \%)$ in group 1.0 and one each in the 0.6 and 0.4 groups had deoxygenated hemoglobin levels less than $1.5 \mathrm{~g} / \mathrm{dl}(\mathrm{P}<0.001)$. Neither HR nor mean arterial blood pressure differed among the groups (Table 2). Decreasing $\mathrm{FiO}_{2}$ was associated with an increased incidence of venous blood identification $(\mathrm{P}<0.001)$. Diagnostic accuracy (i.e., sensitivity) to identify the venous 
blood as venous by all three inspectors was $82.5 \%$ in group 0.2 , $77.5 \%$ in group 0.4 and $72.5 \%$ in group 0.6 versus vs. $37.5 \%$ in group 1.0 ( $\mathrm{P}<0.001$; Fig. 1).

\section{Discussion}

Although life-threatening events are rare in percutaneous central venous catheterization, the technical complication rates have ranged from $3-25 \%$ in patients $[1,2]$, with inadvertent arterial puncture rates being as high as $8 \%$ [11]. Recommended measures to verify arterial puncture during needle localization of the central vein (i.e., venous verification technique) include observation of blood flow and color [5], manometry [12], blood gas analysis [3,13] and real-time ultrasound imaging [14-17]. However, pressure monitoring can be misleading because the Teflon catheter may kink as it is advanced over the needle into the artery and provide a dampened tracing that resembles a venous waveform. Introduction of air bubbles into the arterial circulation can also occur with this method. Blood gas analysis is time-consuming. In addition, in anesthetized patients whose lungs are being ventilated with $\mathrm{FiO}_{2}>0.6$ (and especially in those whom cardiac output is increased) central venous oxygen tension could be greater than $100 \mathrm{mmHg}$ [7]. Recently, ultrasound imaging for central venous catheter placement has gained popularity because of its benefits, including rapid vein localization, a reduction in needle attempts, and fewer complications (i.e., carotid artery puncture) [14-17]. In particular, real-time ultrasound evaluation provides a comprehensive assessment of venous structures and aids practitioners with limited experience as well as catheterization of patients with difficult anatomy [14]. Indeed, recent data with the ultrasound-guided technique demonstrates that only a single-stick is required in $98.5 \%$ of IJV cannulations and that the risk of arterial puncture is $0.3 \%$ [18]. However, inadvertent arterial penetration and dilation still remains a problem despite ultrasound guidance and can result in significant morbidity and even mortality [19]. Moreover, this technique requires a sophisticated instrument and additional time.

A blood color test is simple, efficient and safe but subjective, especially if the patient is receiving supplemental oxygen during the insertion procedure. Although it has been traditionally assumed that $5 \mathrm{~g}$ of deoxygenated hemoglobin per $\mathrm{dl}$ of capillary blood is required for the detection of cyanosis, mild cyanosis can clearly be observed at lower values $[6,20]$. Likewise, the color of the venous blood becomes darker as deoxygenated hemoglobin concentrations increase. In the present study, a $\mathrm{FiO}_{2}$ below 0.6 significantly increased deoxygenated hemoglobin concentrations in the central venous blood $\left(47 \%\right.$ at $\mathrm{FiO}_{2} 0.6,63 \%$ at $\mathrm{FiO}_{2} 0.4$ and $66 \%$ at $\mathrm{FiO}_{2} 0.2$, as compared with a $\mathrm{FiO}_{2}$ value of $1.0(\mathrm{P}<0.001)$ and thereby facilitated the discrimination of venous from arterial blood. We would recommend administering the lowest $\mathrm{FiO}_{2}$ (below 0.6) during central line placement under general anesthesia, if pulse oximeter readings are within an acceptable range $\left(\mathrm{SpO}_{2}>90 \%\right)$. This approach should help reduce unplanned arterial dilations or cannulation, especially in a situation when ultrasound is not available.

In the present study, progressive lowering of $\mathrm{FiO}_{2}$ from 1.0 to 0.2 only modestly decreased $\mathrm{SvO}_{2}$ in the central vein, despite a marked decrease of $\mathrm{PaO}_{2}$. This finding may be explained by the sigmoid shape of the oxyhemoglobin dissociation curve: the arterial blood oxygen content will be on the flat part of the dissociation curve for a $\mathrm{FiO}_{2}$ greater than 0.21 (our lowest $\mathrm{FiO}_{2}$ ). Nevertheless, deoxygenated hemoglobin concentrations in the central vein increased by $63 \%$ and $66 \%$ at a $\mathrm{FiO}_{2}$ of 0.4 and 0.2 , respectively, as compared with the value at $1.0(\mathrm{P}<0.001)$. The greater the deoxygenated hemoglobin contents as $\mathrm{FiO}_{2}$ decreases, the more readily venous blood will be discriminated from the arterial blood (Fig. 1). This hypothesis is supported by a previous study which demonstrated an apparent central cyanosis at deoxygenated hemoglobin concentrations of $1.5 \mathrm{~g} /$ $\mathrm{dl}$ or more, with a threshold of $1.0-1.5 \mathrm{~g} / \mathrm{dl}$ [19]. Indeed, none in the $\mathrm{FiO}_{2} 0.2$ group, whereas 11 patients $(27.5 \%)$ in the $\mathrm{FiO}_{2} 1.0$ group, had deoxygenated hemoglobin concentrations less than $1.5 \mathrm{~g} / \mathrm{dl}$.

However, the blood color test may be affected by multiple factors including hemoglobin content, lighting and interobserver variation. Moreover, in patients with high cardiac output, both arterial and venous blood would be red in spite of a low $\mathrm{FiO}_{2}$. In contrast, in patients with profound hypotension or marked arterial oxyhemoglobin desaturation, arterial puncture is not easy to identify by the pulsatile flow into the syringe and the bright-red color of the blood. Therefore, assessing the blood sample by visual inspection may not be at all definitive in every patient. Since there is no single unequivocal best modality to locate the central vein, although ultrasound imaging and manometry are becoming standards of practice, familiarity with multiple techniques is advisable.

It is a standard practice to administer a $\mathrm{FiO}_{2}$ of 1.0 to maximize the oxygen reserve during induction of and emergence from anesthesia [8]. In the present study, we administered $100 \%$ oxygen until the time of endotracheal intubation. In addition, $\mathrm{SpO}_{2}$ was monitored throughout the study to avoid unacceptable desaturation $\left(\mathrm{SpO}_{2}<90 \%\right)$, and no one developed hypoxemia in any group. Nevertheless, hypoxemia may occur in patients whose hemodynamics are unstable during the induction of anesthesia, especially in the low $\mathrm{FiO}_{2}$ group. A low $\mathrm{FiO}_{2}$ technique should therefore be recommended in clinically safe patients.

In conclusion, the administration of low oxygen fraction 
$\left(\mathrm{FiO}_{2}<0.6\right)$ during catheterization increased deoxygenated hemoglobin concentrations and made the color of the central venous blood darker, facilitating the recognition by clinicians of its venous origin. This technique is easy to perform and may help to determine proper placement in percutaneous central venous catheterization, diminishing the risk of arterial injury from unplanned arterial dilations or cannulas. Nevertheless, discrimination using blood color is not at all definitive and there is no single unequivocal best modality to locate the central vein, and thus familiarity with multiple techniques is advisable.

\section{References}

1. McGee DC, Gould MK. Preventing complications of central venous catheterization. N Engl J Med 2003; 348: 1123-33.

2. Domino KB, Bowdle TA, Posner KL, Spitellie PH, Lee LA, Cheney FW. Injuries and liability related to central vascular catheters: a closed claim analysis. Anesthesiology 2004; 100: 1411-8.

3. Jobes DR, Schwartz AJ, Greenhow DE, Stephenson LW, Ellison N. Safer jugular vein cannulation: recognition of arterial puncture and preferential use of the external jugular route. Anesthesiology 1983; 59: 353-5.

4. Guilbert MC, Elkouri S, Bracco D, Corriveau MM, Beaudoin N, Dubois MJ, et al. Arterial trauma during central venous catheter insertion: Case series, review and proposed algorithm. J Vasc Surg 2008; 48: 918-25.

5. Neustein SM, Narang J, Bronheim D. Use of the color test for safer internal jugular vein cannulation. Anesthesiology 1992; 76: 1062.

6. Stadie WC. The oxygen of the arterial and venous blood in pneumonia and its relation to cyanosis. J Exp Med 1919; 30: 215-40.

7. Landow L. Another problem in differentiating between carotid artery and jugular venous cannulation. Anesthesiology 1992; 76: 1061-2.

8. Ganter MT, Hofer CK, Pitter J. Postoperative intravascular fluid therapy. In: Anesthesia. 7th ed. Edited by Miller RD: Philadelphia, Churchill Livingstone. 2009, pp 2783-803.
9. Henderson J. Airway management in the adult. In: Anesthesia. 7th ed. Edited by Miller RD: Philadelphia, Churchill Livingstone. 2009, pp 1573-610.

10. Erdfelder E, Faul F, Buchner A. GPOWER: A general power analysis program. Behav Res Methods Instrum Comput 1996; 28: 1-11.

11. Wisborg T, Flaatten H, Koller ME. Percutaneous placement of permanent central venous catheters: experience with 200 catheters. Acta Anaesthesiol Scand 1991; 35: 49-51.

12. Ezaru CS, Mangione MP, Oravitz TM, Ibinson JW, Bjerke RJ. Eliminating arterial injury during central venous catheterization using manometry. Anesth Analg 2009; 109: 130-4.

13. Schroeder RA, Barbeito A, Bar-Yosef S, Mark JB. Cardiovascular monitoring. In: Anesthesia. 7th ed. Edited by Miller RD: Philadelphia, Churchill Livingstone. 2009, pp 1267-328.

14. Wigmore TJ, Smythe JF, Hacking MB, Raobaikady R, MacCallum NS. Effect of the implementation of NICE guidelines for ultrasound guidance on the complication rates associated with central venous catheter placement in patients presenting for routine surgery in a tertiary referral centre. Br J Anaesth 2007; 99: 662-5.

15. Hind D, Calvert N, McWilliams R, Davidson A, Paisley S, Beverley $\mathrm{C}$, et al. Ultrasonic locating devices for central venous cannulation: meta-analysis. BMJ 2003; 327: 361.

16. Leung J, Duffy M, Finckh A. Real-time ultrasonographically guided internal jugular vein catheterization in the emergency department increases success rates and reduces complications: a randomized, prospective study. Ann Emerg Med 2006; 48: 540-7.

17. Feller-Kopman D. Ultrasound-guided central venous catheter placement: the new standard of care? Crit Care Med 2005; 33: 1875-7.

18. Cavanna L, Civardi G, Vallisa D, Di Nunzio C, Cappucciati L, Bertè $\mathrm{R}$, et al. Ultrasound-guided central venous catheterization in cancer patients improves the success rate of cannulation and reduces mechanical complications: a prospective observational study of 1,978 consecutive catheterizations. World J Surg Oncol 2010; 8: 91.

19. Blaivas M. Video analysis of accidental arterial cannulation with dynamic ultrasound guidance for central venous access. J Ultrasound Med 2009; 28: 1239-44.

20. Goss GA, Hayes JA, Burdon JG. Deoxyhaemoglobin concentrations in the detection of central cyanosis. Thorax 1988; 43: 212-3. 